\title{
Effect of selected drugs used in asthma treatment on morphology and elastic properties of red blood cells
}

This article was published in the following Dove Press journal:

International Journal of Nanomedicine

26 January 2011

Number of times this article has been viewed

\author{
Anna Zuk \\ Marta Targosz-Korecka \\ Marek Szymonski \\ Research Centre for Nanometer-Scale \\ Science and Advanced Materials, \\ Faculty of Physics, Astronomy, \\ and Applied Computer Science, \\ Jagiellonian University, Reymonta 4, \\ 30-059 Krakow, Poland
}

Background: The main function of red blood cells is to transport oxygen to all parts of the body with the help of hemoglobin. Other proteins of the cell membrane can attach xenobiotics (eg, drugs) from the blood and transport them throughout the body. Only drugs able to bind to the membrane of the red blood cell can modify its structure and elastic properties. The morphology and local elastic properties of living red blood cells incubated with drug solutions commonly used in the treatment of severe asthma were studied by atomic force microscopy and nanoindentation with an atomic force microscopy tip.

Methods: The elasticity modules of native red blood cells, as well as those incubated with two types of drugs, ie, aminophylline and methylprednisolone, were determined from experimentally measured nanoindentation curves.

Results: The elasticity modules of erythrocytes incubated with aminophylline were substantially higher than those obtained for nonincubated native, ie, healthy, red blood cells.

Conclusion: The increase of the elasticity module obtained for aminophylline can reduce the cell's ability to bind oxygen and transport it through capillaries.

Keywords: nanoindentation, atomic force microscopy, erythrocytes, elasticity, asthma

\section{Introduction}

In recent years, use of atomic force microscopy (AFM) in the physiological environment has enabled investigation of the properties of living cells. ${ }^{1,2}$ The force spectroscopy mode of AFM allows for measurements of tip-sample interaction force as a function of their separation at the nanometer scale, and offers yet another category of information, characterizing the micromechanical properties of cellular systems and helping us to understand the functional and physiological properties of cells. The numerous applications of the method include AFM measurement of stiffness abnormalities in red blood cells caused by thalassemia (deficiency of glucose 6-phosphate dehydrogenase) ${ }^{3}$ and significant lowering of the stiffness in various cancerous cells. ${ }^{4}$ Furthermore, AFM is also used to monitor dynamic cellular processes, such as cell growth, exocytosis, endocytosis, ${ }^{5}$ and changes in the shape of red blood cells caused by hyperosmotic solution.

The main physiological function of red blood cells, the major component of blood, is related to the capability of the cell membrane to bind and transport oxygen to all parts of the body via hemoglobin. Other membrane proteins interact with so-called xenobiotics (eg, drugs) from the blood and facilitate their transportation within the circulation. Some drugs which bind with the cell membrane can modify the structure and elastic properties of red blood cells, and may eventually cause hemolysis of the erythrocyte. ${ }^{6}$ 
In this work, nanoindentation with the AFM tip is used to characterize viscoelastic changes in erythrocytes due to incubation with drugs often used in the treatment of severe asthma, ie, aminophylline and methylprednisolone. The main goal of this study was to determine if intravascular injection of these drugs can affect the main physiological functions of red blood cells related to their mechanical properties, eg, their ability to bind and transport oxygen. It is shown that both drugs, ie, aminophylline and methylprednisolone, have a significant effect on the properties of the cell membrane, resulting in a noticeable change in red blood cell stiffness and morphology, which correlates with drug concentration and incubation time.

\section{Materials and methods} Sample preparation

Erythrocytes are collected from complete blood samples taken from healthy volunteers. The main buffer solution was comprised of phosphate buffer solution, $1 \%$ bovine serum albumin, and $0.5 \%$ glucose in volume proportions of 20:4:1. All compounds were obtained from Sigma-Aldrich (St Louis, MO). Initially, fresh blood was diluted in the mixture of the main buffer solution and one of the investigational drugs. Typically, three different concentrations of drugs $(1 \mathrm{mg} / \mathrm{mL}, 0.1 \mathrm{mg} / \mathrm{mL}, 0.01 \mathrm{mg} / \mathrm{mL})$ were used. In the next step, the blood was mixed with this solution for two, six, and 12 hours in a hematological mixer at room temperature. After the assigned time period, one drop of the suspension was placed on a glass substrate treated with poly-L-lysine (Mäntzel Gläser, Germany) and was then incubated for one hour at $37^{\circ} \mathrm{C}$. Afterwards, one drop of $0.5 \%$ glutaraldehyde was added for 1.5 minutes to fix the red blood cell membrane to the substrate. Finally, the pretreated cells were washed with phosphate buffer solution to remove the unbound cells and the glutaraldehyde.

\section{Nanoindentation with an AFM tip}

Local elastic properties of the erythrocytes were determined from the nanoindentation curves, ie, loading force versus distance dependences taken under tip indent conditions. The force-distance measurements are performed using an Auto Probe CP-2 AFM (Park Scientific Instruments, South Korea) equipped with a silicon nitride tip mounted on a silicon nitride cantilever having a spring constant of about $0.01 \mathrm{~N} / \mathrm{m}$ (Microlevers C, Veeco, Woodbury, NY). The indentations were performed with a constant loading rate over the entire indentation range offered by the $\mathrm{Z}$ scanner. All force values were calculated by using the nominal values of the spring constant, because verifying thermal tune analysis done with the PicoForce AFM (Veeco) instrument yielded values close to the nominal one with an accuracy of $15 \%$. All measurements were carried out in a phosphate buffer solution. Prior to each force-distance measurement on the red blood cells, a corresponding dependence was measured on a glass substrate in order to avoid artifacts associated with possible contamination of the tip surface. Every indentation step performed was followed by selection of the new indentation site on the erythrocyte membrane using an optical microscope-based tip positioning procedure with respect to the cell center. ${ }^{3}$ Approximately 1000 indentation curves were recorded for each sample. Because the elasticity of the cells could change with time, a special effort was made to limit the time of the indentation curve acquired on each individual cell sample to 30 minutes. It should be pointed out that the cell elasticity measurements by means of nanoindentation with an AFM tip mainly provide information on stiffness of the cell membrane, which is probed point by point over the cell area. Such a method could yield different results from those measured with macroscopic techniques, and provide the elasticity value of the entire cell volume.

\section{Elasticity module calculations}

Elasticity module can be calculated using the Hertz model ${ }^{7}$ which describes the elastic deformation of two bodies in contact under load. The Hertz's approach was extended by Sneddon, ${ }^{8}$ who assumed an appropriate shape of the indenter causing deformation of the elastic half space. In our work, we followed the relationship between the force and the indentation depth as approximated by Sneddon. Two predictions of the model were compared with the experimental indentation curves. In the first one, with the AFM tip approximated by a paraboloid, the force as a function of indentation is described by the following equation:

$$
F_{\text {parab }}(\Delta z)=\frac{4 \sqrt{R}}{3} E^{\prime} \Delta z^{\frac{3}{2}}
$$

where $\Delta z$ is indentation depth, $R$ is the radius of curvature, and $E^{\prime}$ is the reduced elasticity module.

$$
E^{\prime} \text { is defined by } \frac{1}{E^{\prime}}=\frac{1-\mu_{0}^{2}}{E_{0}}+\frac{1-\mu_{P}^{2}}{E_{P}}
$$

where $E_{p}, E_{o}$ are the elasticity modules of the sample and the tip, respectively, and $\mu_{p}, \mu_{0}$ are the respective Poisson ratios. In the second case, the shape of the tip is approximated 
by a cone, and this dependence is approximated by the equation:

$$
F_{\text {cone }}(\Delta z)=\frac{2 E^{\prime}}{\pi \tan \alpha} \Delta z^{2}
$$

with the notation as above. When $E_{p} \ll E_{0}$, the equation describing $E^{\prime}$ can be approximated by

$$
\frac{1}{E^{\prime}} \approx \frac{1-\mu_{P}^{2}}{E_{p}}
$$

For soft materials, especially biological samples, the Poisson ratio ranges from 0.49 to 0.499 . For the approximation used in this work, we assumed the Poisson ratio to be 0.5 , according to Hertz. ${ }^{7}$

\section{Data calibration and analysis}

Because in our setup the indentation curve is obtained by cantilever deflection measurements as a function of the $\mathrm{Z}$ coordinate change, the calibration dependence showing the relationship between a voltage signal from the position-sensitive detector and the distance was measured (see Figure 1). The calibration curve was measured on glass with a poly-Llysine surface. A linear regression procedure was used to fit the equation shown below to the linear part of the calibration dependence:

$$
F[N]=\alpha\left[\frac{\mu m}{m V}\right] * k\left[\frac{N}{m}\right] * U[m V]^{*} 10^{-6}
$$

where $F$ is the exerted force in Newtons, $a$ is the proportionality coefficient, $k$ is the cantilever spring constant, and $U$ is the voltage signal reflecting the cantilever deflection in the course of indentation. Finally, the indentation curve can be evaluated using that part of the experimental dependence which corresponds to the physical contact of the AFM tip with the cell membrane (see Figure 1B). In order to determine the point of contact, a linear regression fit is made to that part of the calibration curve which corresponds to the lack of interactions (horizontal line on Figure 1B), and then the correlation function is calculated for the deviation of every data point with respect to the best fit line. The indentation values are taken as differences between $\mathrm{Z}$ arguments of the experimental dependence measured for the erythrocytes and the calibration curve.

\section{Results}

A typical example of the indentation data for red blood cells incubated with $0.1 \mathrm{mg} / \mathrm{mL}$ methylprednisolone for two hours is presented in Figure 2. It shows that the force versus indentation function is fitted correctly with a polynomial corresponding to the predictions of the Sneddon's model for a paraboloidal tip 1), ie, $y=A+B x^{3 / 2}$.

Therefore, the elasticity modules are calculated from the best fit value of the parameter B and equations (1) and (4).

\section{Erythrocytes in buffer solution}

As a reference to stiffness measurements for erythrocytes incubated with different drugs, we measured the indentation curves for the cells incubated in the main buffer solution only. Stiffness changes as a function of incubation time were observed. Results are shown as histograms in Figure 3, with the bin size reflecting a confidence zone of the measurements. The average values of the elasticity modules were obtained by fitting the Gaussian distribution to the histograms. Justification for using a normal distribution function for analysis of the experimental data was provided by performing the Shapiro-Wilk normality test. This procedure indicated
A

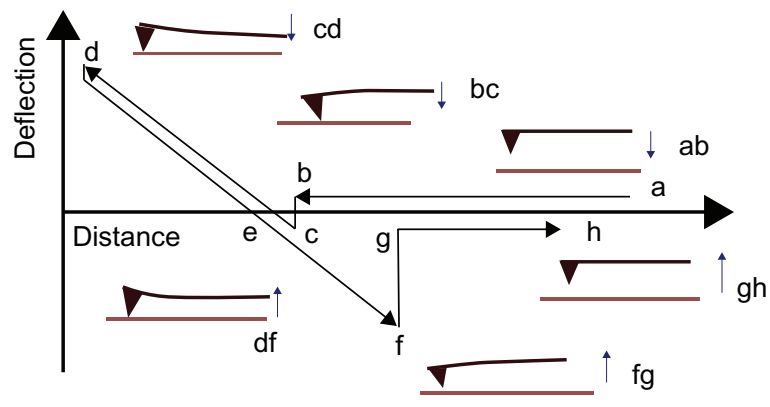

B

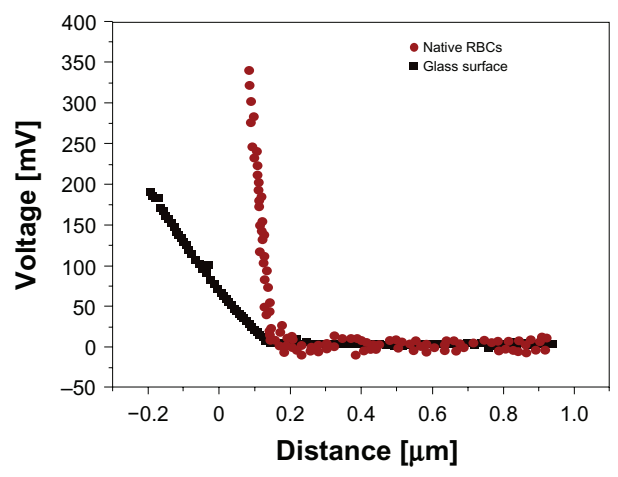

Figure I Cantilever deflection dependence on the tip sample distance ( $Z$ coordinate). A) Schematic sketch with drawings of the cantilever bending corresponding to various segments of dependence. B) A typical experimental indentation curve for the healthy blood cell and the calibration curve taken on the glass surface. 


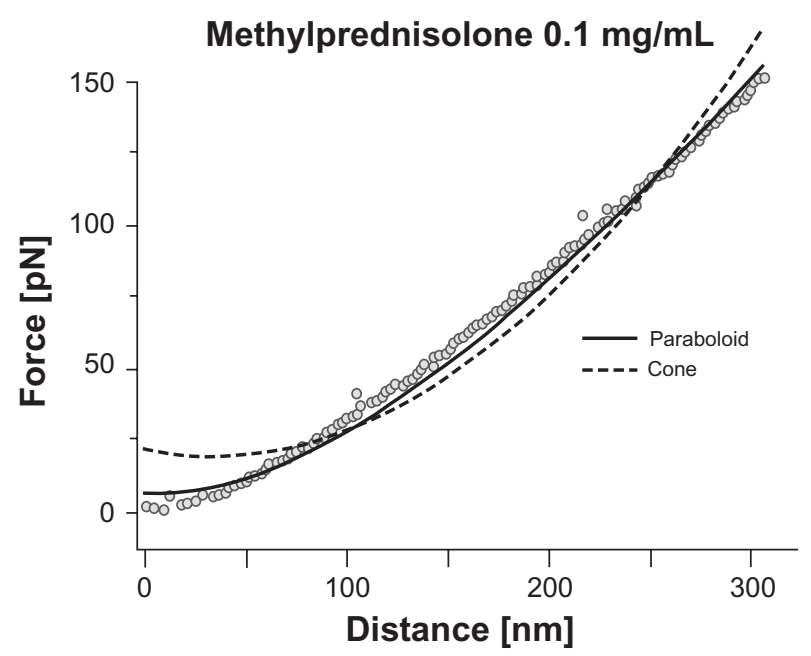

Figure 2 An example of the indentation curve obtained for red blood cells incubated with methylprednisolone $0.1 \mathrm{mg} / \mathrm{mL}$ for two hours. Experimental points (open circles) are shown together with the best fit of the theoretical dependences predicted for a paraboloidal tip (solid curve) and a conical one (broken curve). The dependence represents the average of more than 100 curves. The size of data points on the curve corresponds to the uncertainty resulting from the averaging.

that all distributions from Figure 3 are normal at the level of $\alpha=0.07$. Furthermore, the equality of variance was successfully verified with a Levene's test, and the statistical evaluation of the difference between the distributions was done by an analysis of variance (ANOVA) test. The results of the ANOVA test showed that the distributions were completely different at the level of $\alpha=0.01$. The time dependence of the average elasticity module is shown in Figure 4 . The error bars seen in this figure represent half-widths of the normal distributions from Figure 3. It can be concluded that stiffness of the erythrocyte membrane increases with time of incubation in the main buffer solution.

\section{Erythrocytes incubated with aminophylline}

The therapeutic concentrations of aminophylline range from 0.01 to $0.02 \mathrm{mg} / \mathrm{mL}$. In higher concentrations, the drug can be toxic to patients. ${ }^{9,10}$ A typical force versus indentation dependence for red blood cells incubated with aminophylline at a concentration of $0.01 \mathrm{mg} / \mathrm{mL}$ is shown in Figure 2. Comparison of the cell morphologies and the force versus indentation curves obtained for the native red blood cells and the ones incubated for six hours with aminophylline at a concentration of $0.01 \mathrm{mg} / \mathrm{mL}$ is shown in Figure 5 .

The erythrocyte images seen in Figure 5 reflect the most commonly observed changes in red blood cell morphology resulting from incubation with aminophylline. For the control group, both the erythrocyte diameter of $7.4 \pm 0.1 \mu \mathrm{m}$ and height of $1.6 \pm 0.1 \mu \mathrm{m}$ fall within the range expected for healthy cells (6-8 $\mu \mathrm{m}$ and $1-2 \mu \mathrm{m}$, respectively). In the case of cells treated with aminophylline, structural changes
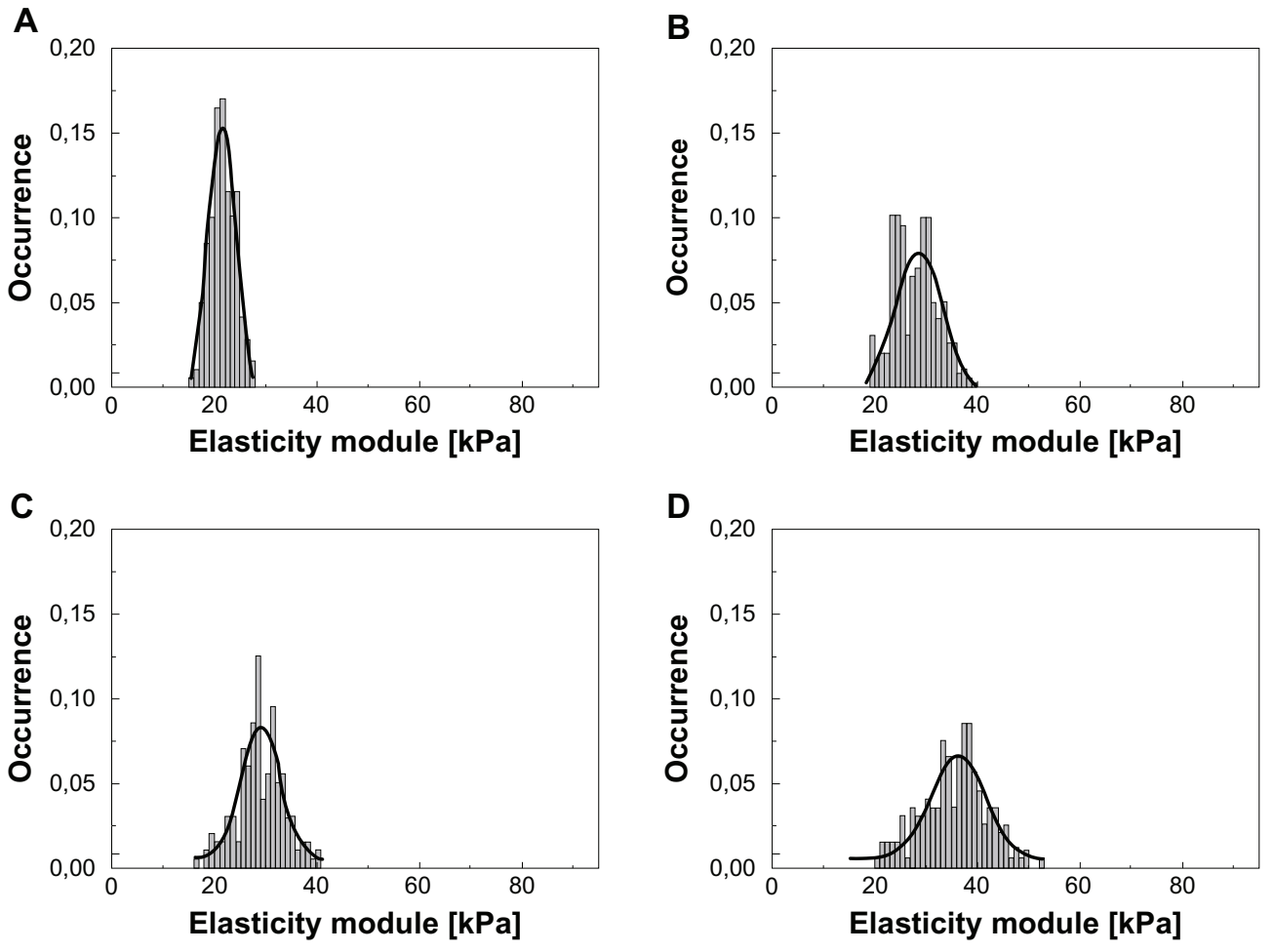

Figure 3 Histograms of the elasticity module for red blood cells incubated with the main buffer solution for A) 0 hours, B) two hours, C) six hours, and D) I2 hours. 


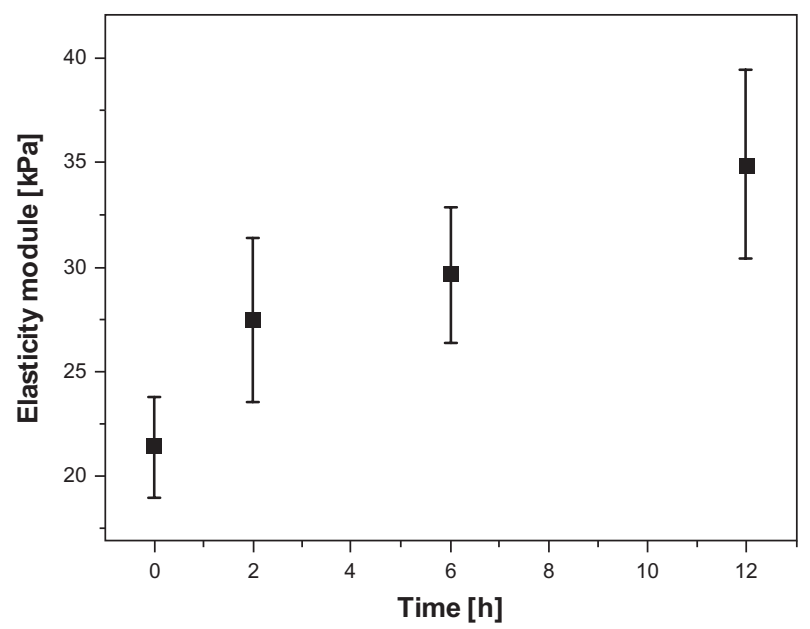

Figure 4 The dependence of the red blood cell elasticity module on incubation time in the main buffer solution. The error bars shown represent half-widths of the normal distributions from Figure 3.

of the membrane appear undulated in comparison with the control, which implies that the cells are at the initial stage of transformation into an echinocyte-like form. We also noticed greater sizes of such cells, ie, $8.3 \pm 0.1 \mu \mathrm{m}$ in diameter and up to $2.3 \pm 0.1 \mu \mathrm{m}$ in height.

Histograms of the experimentally determined elasticity modules are shown in Figure 6. The normality test shows that the $C$ distribution is normal at the level of $\alpha=0.01$ and the remaining distribution at $\alpha=0.06$. Furthermore, the Levene's test shows that all histograms have equal variances, and the results of the ANOVA test show that all distributions are different at the level of $\alpha=0.01$.

The experimentally determined changes in red blood cell stiffness due to incubation with aminophylline at various concentrations are shown in Figure 7. It is seen that the expected values of the elasticity modules are significantly different (by a factor of almost three) from those obtained for the erythrocytes incubated with the main buffer solution. Furthermore, it is found that the value of the elasticity module is the highest after six hours of incubation and increases with concentration of the drug in solution, although the statistical error of this type of evaluation is rather large.

\section{Erythrocytes incubated with methylprednisolone}

The morphology of red blood cells incubated with methylprednisolone $1 \mathrm{mg} / \mathrm{mL}$ was modified considerably, as shown in Figure 8. The external surface of the cell shows clear bumpy modulations which indicate significant changes occurring in the membrane lipid bilayer and/or in its supporting 2D spectrin-dominated network. Statistical analysis of the histograms (not shown) depicting experimentally determined distributions of the elastic modules for the cells indicates that all distributions, except for one, are normal at the level of $\alpha=0.06$, and only for incubation with $1 \mathrm{mg} / \mathrm{mL}$ for two hours at $\alpha=0.065$. Furthermore, the Levene's test shows that all histograms have equal variances, and the ANOVA test indicates that they are significantly different at the level of $\alpha=0.05$. The expected values of the elasticity modules are shown in Figure 9.

\section{Discussion}

It is widely assumed that the elastic properties of red blood cells are determined by the stiffness and internal structure of the cell skeleton. ${ }^{11-17}$ However, there are reports suggesting that the elastic properties of the lipid bilayer cell membrane could also be quite important for overall cell stiffness. ${ }^{6,13,18-20}$ In particular, membrane elasticity could be significantly affected by intercalation with specific molecules, such as amphiphilic molecules ${ }^{6}$ and stress hormones. ${ }^{20}$
A

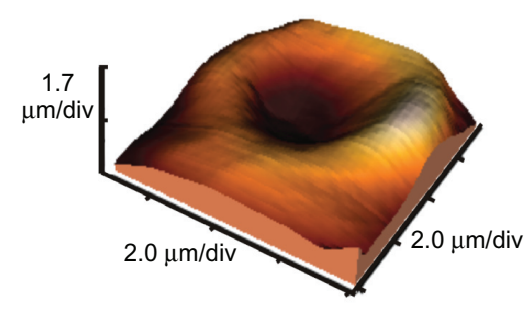

B

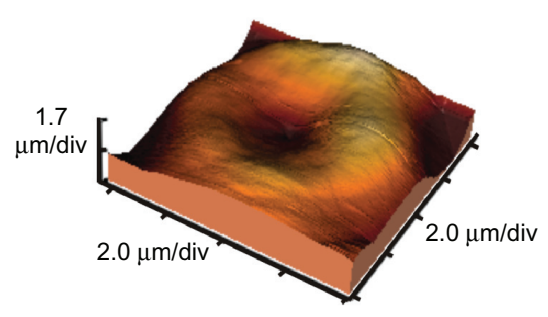

C

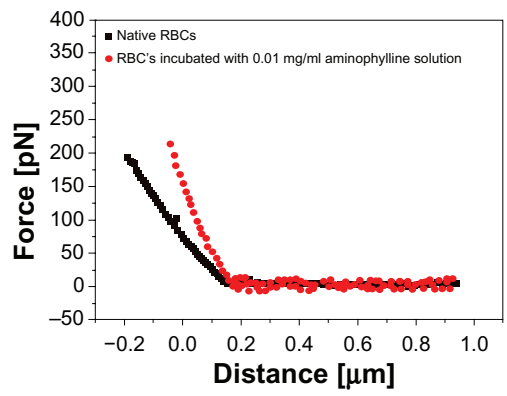

Figure 5 Atomic force microscopic images of the native red blood cells and the cells incubated for six hours with aminophylline $0.0 \mathrm{I} \mathrm{mg} / \mathrm{mL}$ (A and $\mathbf{B}$ ). C) Comparison of force versus indentation curves obtained for the native red blood cells and those incubated for six hours with aminophylline $0.01 \mathrm{mg} / \mathrm{mL}$. The curves represent the result of averaging of more than 100 curves. Point sizes represent the uncertainty arising from the averaging process. 

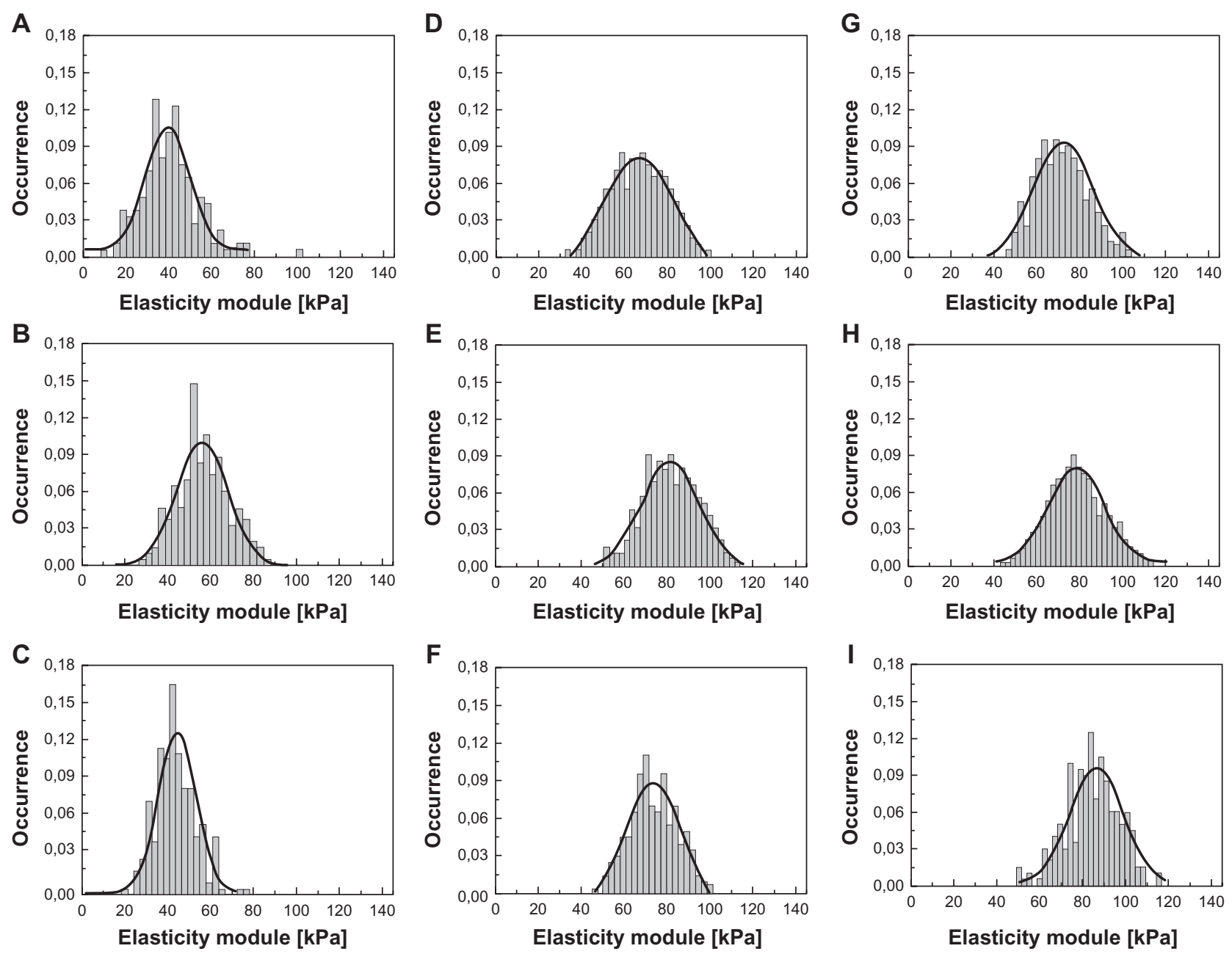

Figure 6 Histograms of red blood cell elasticity modules incubated with aminophylline for two hours, $0.01 \mathrm{mg} / \mathrm{mL}$ (A); six hours, $0.01 \mathrm{mg} / \mathrm{mL}$ (B); $12 \mathrm{hours}, 0.01 \mathrm{mg} / \mathrm{mL}$ (C); two hours, $0.1 \mathrm{mg} / \mathrm{mL}$ (D); six hours, $0.1 \mathrm{mg} / \mathrm{mL}$ (E); 12 hours, $0.1 \mathrm{mg} / \mathrm{mL}$ (F); two hours, $1.0 \mathrm{mg} / \mathrm{mL}$ (G); six hours, $1.0 \mathrm{mg} / \mathrm{mL}$ (H); 12 hours, $1 \mathrm{mg} / \mathrm{mL}$ (I).
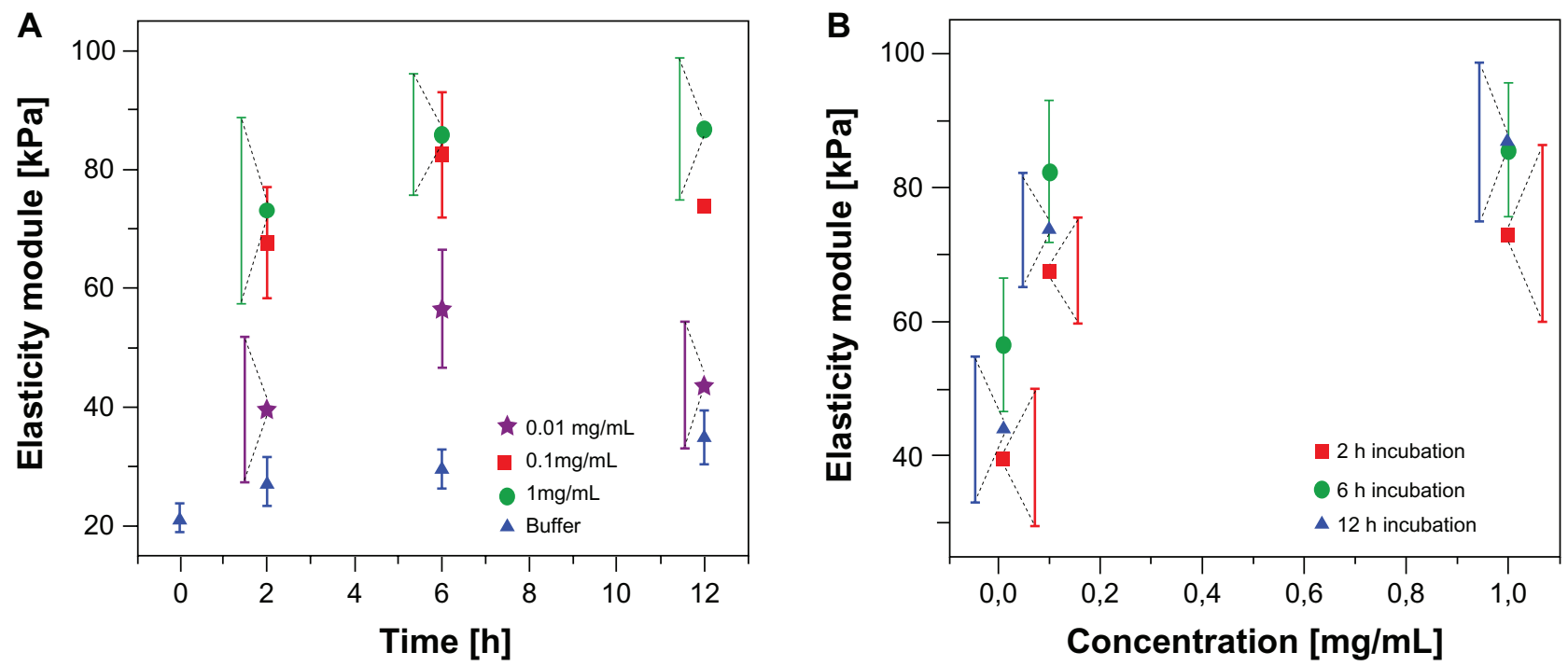

Figure 7 Elasticity modules of red blood cells incubated with aminophylline displayed as a function of incubation time (A) and concentration (B). Error bars represent half-widths of the normal distributions from Figure 6. 


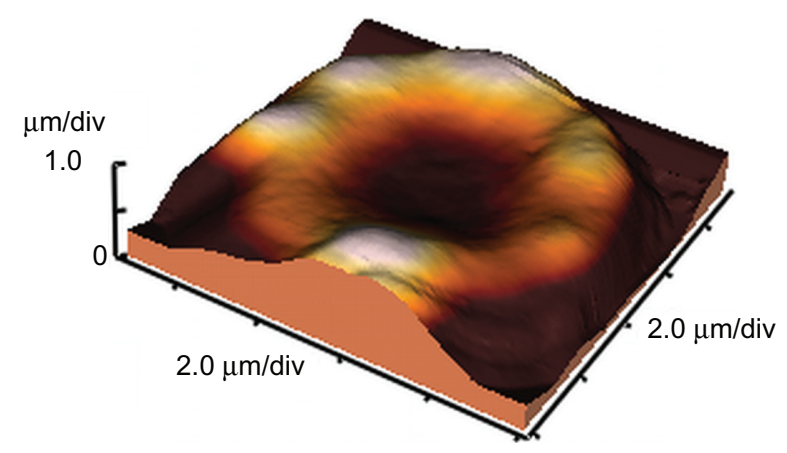

Figure 8 Surface morphology of the erythrocyte incubated with methylprednisolone for 12 hours at a concentration of $\mathrm{I} \mathrm{mg} / \mathrm{mL}$. Imaging was performed in buffer solution (pH 7.4) with contact mode atomic force microscopy.

The results presented in this work indicate that the elasticity modules of the red blood cell increase (ie, cell stiffness increases) with increasing concentrations of aminophylline (Figure 6B). An interesting observation in our analysis is that the elasticity changes in red blood cells treated with aminophylline are not monotonic with time. The biggest value of the elasticity module is reached after six hours of incubation and a small decrease after 12 hours can be explained by its half-life inside the erythrocyte membrane. ${ }^{9,10}$ Aminophylline is used to prevent and treat wheezing, shortness of breath, and difficulty in breathing caused by asthma, chronic bronchitis, and other lung diseases. It contains a 2:1 mixture of theophylline and ethylenediamine. The latter compound is responsible for the increased water solubility of the drug. Theophylline, a methylated xanthine compound, can interact with the erythrocyte membrane causing inactivation of phosphodiesterase molecules and increasing intracellular concentration of adenosine triphosphate, decreased potassium ion flow away from the cell, an increase of the protein phosphorylation level, and, as a result, affecting erythrocyte membrane stability. ${ }^{21}$ Therefore, there are two possible ways the drug molecules could influence the functionality of red blood cells. Firstly, the interaction of the drugs with the membrane lipid bilayer could alter the transport channels responsible for oxygen penetration through the membrane and subsequently could directly reduce the cell's ability to bind oxygen to hemoglobin. Secondly, the transport properties of the entire cell are diminished by its increase in stiffness and subsequent reduction of deformability, which is necessary for adjustments in cell shape during flow through the microvasculature.

The effect of methylprednisolone on the morphology and stiffness of red blood cells is more complicated than that of the xanthine derivatives. Methylprednisolone is a corticosteroid hormone used to treat allergic disorders and breathing problems, including asthma and chronic obstructive pulmonary disease. In a recent publication, Panin et $\mathrm{al}^{20}$ reported that stress hormones (cortisol, adrenaline, noradrenaline) can bind to red blood cell membranes with a rather high affinity via a complex interplay of hydrogen bonds, as well as hydrophobic and electrostatic interactions. These researchers found that such an interaction of hormones with the membrane results in structural transitions in membrane proteins and phospholipids. Formation of large domains of lipid and lipid-protein complexes is observed which would likely decrease red blood cell elasticity and rheological

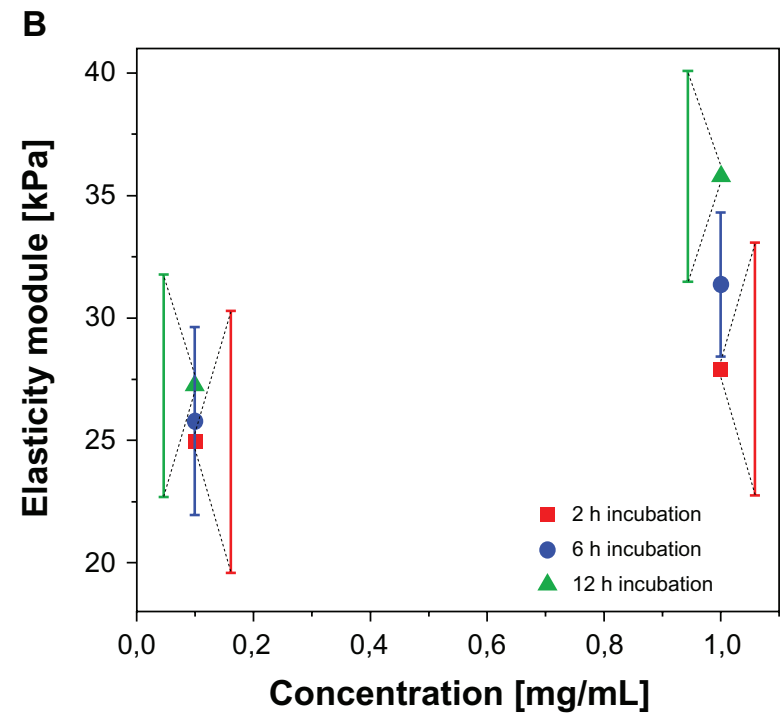

Figure 9 Elasticity modules for red blood cells incubated with methylprednisolone plotted as a function of incubation time (A) and drug concentration (B). Error bars represent half-widths of the normal distributions fitted to the respective histograms. 
properties. We found that the stiffness of red blood cells incubated with a high concentration of methylprednisolone $(1 \mathrm{mg} / \mathrm{mL})$ increases with incubation time in a similar way as for incubation in buffer solution alone (see Figure 9). On the other hand, red blood cell membrane morphology changes significantly (see Figure 8) at this concentration of drug, which could be ascribed to effects similar to those reported by Panin et al. ${ }^{20}$ However, at lower concentrations $(0.1 \mathrm{mg} / \mathrm{mL}$, close to the therapeutic dose) of the drug, the values are consistently lower than those obtained for buffer solution alone, and the effect of reduced red blood cell stiffness remains, even at longer incubation times (12 hours). This is in contrast with the behavior seen for incubation with aminophylline described in the previous section, and consistent with the fact that red blood cell morphology changes at low concentrations of methylprednisolone were not seen in our AFM images.

As already stated in the introduction, the main goal of the present work was to determine whether the stiffness of red blood cells incubated in solutions of selected drugs used in clinical treatment of severe asthma is modified to undesirable levels, and whether indentation with an AFM tip could be an efficient method to quantify the elastic properties of the cells, allowing for determination of expected values of the cell elastic modules. It is found that both drugs, ie, aminophylline and methylprednisolone, have a significant effect on cell membrane properties, causing noticeable changes in red blood cell stiffness and morphology. Our results indicate that red blood cell elasticity is indeed affected by drugs used in the clinical treatment of asthma, and in order to account for the experimentally determined dependences on incubation time, a balanced interplay between stiffness changes in both the cell membrane and the cytoskeleton should be considered. Although direct extrapolation of our results to the clinical setting is limited due to our investigations being performed in vitro and the concentrations of the drugs investigated often being higher than the therapeutic concentrations of these agents in blood $\left(0.01 \div 0.02 \mathrm{mg} / \mathrm{mL}\right.$ for aminophylline ${ }^{9}$ and $0.02 \div 0.05 \mathrm{mg} / \mathrm{mL}$ for methylprednisolone), ${ }^{22}$ the trends seen in our experiments are likely to be of general importance. Based on our results, we can conclude that the basic therapeutic effect of the drugs related to increased opening of breathing arteries might be reduced by using high concentrations of these drugs which have the side effect of lowering the ability of red blood cells to bind and transport oxygen in the human vascular system. Finally, we have demonstrated that nanoindentation with an AFM tip is a simple and reliable method for obtaining a quantitative measure of red blood cell stiffness, and could be considered as a possible diagnostic method for evaluation of the functional properties of the cell.

\section{Acknowledgment}

The financial support of the Polish Foundation for Science for this research is gratefully acknowledged.

\section{Disclosure}

The authors report no conflicts of interest in this work.

\section{References}

1. Henderson ER. Atomic force microscopy of living cells. Prog Surf Sci. 1994;46:39-60.

2. Müller JD, Dufrêne YF. Atomic force microscopy as a multifunctional molecular toolbox in nanobiotechnology. Nat Nanotechnol. 2008;3:261.

3. Dulinska I, Targosz M, Strojny W, et al. Stiffness of normal and pathological erythrocytes studied by means of atomic force microscopy. J Biochem Biophys Methods. 2006;66:1-11.

4. Cross SE, Jin YS, Rao JY, Gimewski JK. Nanomechanical analysis of cells from cancer patients. Nat Nanotechnol. 2007;2:780-783.

5. Xing YH, Lau JM, Zhang S, Yu L. Atomic force microscopy imaging of living cells: A preliminary study of the disruptive effect of the cantilever tip on cell morphology. Ultramicroscopy. 2000;82:297-305.

6. Bazzoni G, Rasia M. Effects of an amphipathic drug on the rheological properties of the cell membrane. Blood Cells Mol Dis. 1998;24: 552-559.

7. Hertz H. Über die berührung fester elastischer körper (on the contact of elastic solids). J Reine Angewandte Math. 1882;94:156-171. (English translation in: Hertz H, Jones, Schott, editors. Miscellaneous Papers, London: Macmillan; 1896).

8. Sneddon IN. The relation between load and penetration in the axisymmetric Boussinesq problem for a punch of arbitrary profile. Int J Eng Sci. 1965;3:47-57.

9. Gulati K, Ray A, Pal G, Vijayan VK. Possible role of free radicals in theophylline induced seizures in mice. Pharmacol Biochem Behav. 2005;82:241-245.

10. Gulati K, Ray A, Pal R, Vijayan VK. Free radicals in drug toxicity: Focus on theophylline. In: Ray A, Gulati K, editors. Current Trends in Pharmacology. New Delhi: IK International; 2007.

11. Mohandas N, Chasis JA, Shohet SB. The influence of membrane skeleton on red cell deformability, membrane material properties and shape. Semin Hematol. 1983;20:225-242.

12. Radmacher M, Fritz M, Kacher CM, Cleveland JP, Hansma PK. Measuring the elastic properties of human platelets with the atomic force microscope. Biophys J. 1996;70:556-557.

13. Hanss M, Koutsouris D. Thermal transitions of red blood cell deformability correlation with membrane rheological properties. Biochem Biophys Acta. 1984;769:461-470.

14. Hoh JH, Schoenenberger CA. Surface morphology and mechanical properties of MDCK monolayers by atomic force microscopy. J Cell Sci. 1994;107:1105-1114.

15. Nowakowski R, Luckham P, Winlove P. Imaging erythrocytes under physiological conditions by atomic force microscopy. Biochim Biophys Acta. 2001;1514:170-176.

16. O’Reilly M, McDonnell L, O'Mullane J. Quantification of red blood cells using atomic force microscopy. Ultramicroscopy. 2001;86:107-112.

17. Vinckier A, Semenza G. Measuring elasticity of biological material by atomic force microscopy. FEBS Lett. 1998;430:12-16. 
18. Svetina S, Kuzman D, Waugh RE, Ziherl P, Zeks B. The cooperative role of membrane skeleton and bilayer in the mechanical behavior of red blood cells. Bioelectrochemistry. 2004;62:107-113.

19. Park YK, Best CA, Badizadegan K, et al. Measurement of red blood cell mechanics during morphological changes. Proc Natl Acad Sci USA. 2010;107:6731-6736.

20. Panin LE, Mokrushnikov PV, Kunitsyn VG. Interaction mechanism of cortisol and catecholamines with structural components of erythrocyte membranes. J Phys Chem B. 2010;114:9462-9473.
21. Schneider R. Results of hemorheologically active treatment with pentoxyphylline in patients with cerebrovascular disease. Angiology. 1989;40:988-991.

22. Booker BM, Magee MH, Blum RA, Lates CD, Jusko WJ. Pharmacokinetic and pharmacodynamic interactions between diltiazem and methylprednisolone in healthy volunteers. Clin Pharmacol Ther. 2002;72:370-382.
International Journal of Nanomedicine

\section{Publish your work in this journal}

The International Journal of Nanomedicine is an international, peerreviewed journal focusing on the application of nanotechnology in diagnostics, therapeutics, and drug delivery systems throughout the biomedical field. This journal is indexed on PubMed Central,

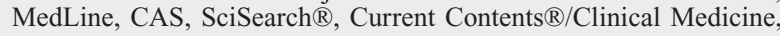

\section{Dovepress}

Journal Citation Reports/Science Edition, EMBase, Scopus and the Elsevier Bibliographic databases. The manuscript management system is completely online and includes a very quick and fair peer-review system, which is all easy to use. Visit http://www.dovepress.com/ testimonials.php to read real quotes from published authors.

Submit your manuscript here: http://www.dovepress.com/international-journal-of-nanomedicine-journal 